\title{
Discussion Paper No. 08-007 \\ A Comparative Study on the Role of Stochastic Trends in U.S. Macroeconomic Fluctuations, 1954-1988
}

Atılım Seymen

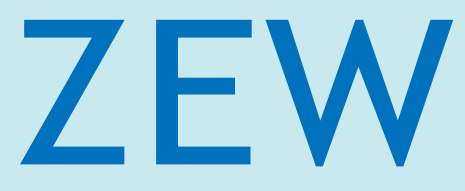

Zentrum für Europäische Wirtschaftsforschung $\mathrm{GmbH}$ Centre for European Economic Research 
Discussion Paper No. 08-007

\title{
A Comparative Study on the Role of Stochastic Trends in U.S. Macroeconomic Fluctuations, 1954-1988
}

\author{
Atılım Seymen \\ Download this ZEW Discussion Paper from our ftp server: \\ ftp://ftp.zew.de/pub/zew-docs/dp/dp08007.pdf
}

Die Discussion Papers dienen einer möglichst schnellen Verbreitung von neueren Forschungsarbeiten des ZEW. Die Beiträge liegen in alleiniger Verantwortung der Autoren und stellen nicht notwendigerweise die Meinung des ZEW dar.

Discussion Papers are intended to make results of ZEW research promptly available to other economists in order to encourage discussion and suggestions for revisions. The authors are solely responsible for the contents which do not necessarily represent the opinion of the ZEW. 


\section{Non-Technical Summary}

This paper analyses and extends two seminal macroeconometric studies by Gali (1999) and King et al. (1991; henceforth KPSW) that use the structural vector autoregression (SVAR) technique with long-run restrictions for identifying macroeconomic shocks and investigating the sources of business cycle fluctuations. Our conclusions build on the findings of Alexius and Carlsson (2001, 2005), who establish that the bivariate Gali model containing labor productivity and hours worked provides a more reliable estimate of technology shocks than the three-variable and six-variable KPSW models, the former of which comprises only the real variables output, consumption and investment and the latter of which adds the nominal variables real balances, nominal interest rate and inflation.

Alexius and Carlsson (2005) obtain that the bias in the three-variable KPSW model when estimating technology shocks is closely related to the lack of a labor input variable. We show in this paper that this finding extends to the six-variable case as well. Therefore, we augment the six-variable model with hours worked to create a seven-variable one and impose the identification restriction of Gali in order to estimate technology shocks together with labor-supply, inflation and real-interest-rate shocks. This augmentation yields several advantages for macroeconometric analysis. First, the dynamic effects of more structural shocks on more macroeconomic variables can be investigated than in a bivariate model. Second, we can check whether the so-called omitted variables bias exists, and if it does, how it affects the identification of macroeconomic mechanisms. Third, we can distinguish between transitory and permanent shocks due to the presence of cointegration in contrast to the bivariate model.

The sample we use is taken from KPSW and Gali (1999) and covers the period 1954:1 to 1988:4. Thus, our findings are almost directly comparable to the findings in these papers as well as to those in Alexius and Carlsson (2001, 2005).

When augmenting the bivariate model to a seven-variable model, we consider several subsets. Our main finding is that the identification restriction in the bivariate model leads to a robust estimation of technology shocks in every subset model as well as in the sevenvariable model. A second finding is that the estimation of inflation and real-interest-rate shocks is not greatly affected by the type of restriction used to identify technology shocks. 
Third, we obtain that the KPSW identification scheme is very sensitive to the presence of nominal variables, whereas the Gali restriction for identifying technology shocks is robust to the inclusion of nominal variables in the VAR. Fourth, the estimated technology measures of both three-variable and six-variable KPSW models contain a significant labor-supply component; i.e., they are mingled with nontechnology and demand measures.

We furthermore investigate the driving forces of business cycles. Whereas Gali (1999) compares the comovements of the business cycle components of macroeconomic variables and KPSW employ forecast error variance decompositions for a similar investigation, we find using historical variance decompositions for the same purpose more suitable. Nontechnology shocks are found to be clearly the main driving force behind cyclical fluctuations. We obtain in particular that permanent demand shocks are more important than others in the fluctuations of output, consumption and investment. Therefore, the findings suggest for theoretical researchers that it is useful to deviate from the RBC paradigm in the business cycle context. The cyclical fluctuations of real balances are explained much better by permanent supply shocks than by demand shocks, whereas the fluctuations of real and nominal interest rates are dominated by demand shocks. One possible explanation of this finding is that the monetary authority reacts to supply shocks by changing the circulated amount of money and to demand shocks by using the interest rate as a policy instrument. Finally, the role played by transitory shocks in the fluctuations of macroeconomic variables is for all of the variables smaller than the role of permanent shocks, which implies that most of the business cycle fluctuations occur when macroeconomic variables converge to new equilibria due to permanent shocks. 


\title{
A Comparative Study on the Role of Stochastic Trends
}

\author{
in U.S. Macroeconomic Fluctuations, 1954-1988
}

\author{
Atılım Seymen*
}

January 2008

\begin{abstract}
The paper attempts to provide an appropriate model specification for identifying technology and other macroeconomic shocks in a structural VAR framework. The investigation is conducted based on two seminal structural VAR studies by Gali (1999) and King et al. (1991). The models of these studies are compared and contrasted, and then modified based on the findings. The analysis builds on two studies of Alexius and Carlsson $(2001,2005)$ that examine the ability of structural VAR models to identify technology shocks. The original and augmented models are used for investigating the driving forces behind business cycle fluctuations.
\end{abstract}

JEL classification: C32, C51, C52

Keywords: Structural Vector Autoregression, Long-Run Restrictions, Error Variance Decomposition

\footnotetext{
*I am greately indebted to Bernd Lucke, Beatriz Gaitan and Olaf Posch for their comments and suggestions on earlier drafts of the paper. The work also benefited from participation in the following: two seminars at Ege University and Izmir University of Economics in Izmir, the 4th PhD Conference in Economics in Volterra, at the Macroeconometric Workshop at the DIW Berlin in 2006 and the 7th Macroeconometric Workshop at the IWH Halle. Finally, I received a great deal of support while writing large parts of the paper during my tenure as a research assistant at the Institute for Growth and Business Cycles of the University of Hamburg. Any errors are my own.

Center for European Economic Research (ZEW), P.O. Box 103443, D-68304 Mannheim, Germany. E-mail: seymen@zew.de
} 


\section{Introduction}

This paper compares and extends two seminal macroeconometric studies by Gali (1991) and King et al. (1991; henceforth KPSW) that use the structural vector autoregression (SVAR) technique with long-run restrictions for identifying macroeconomic shocks and investigating the sources of business cycle fluctuations. As noted by Faust and Leeper (1997), checking for consistency of results across various small SVAR models can help to maintain the convenience of small models. If two different SVAR models arrive at similar results, then the researcher finds clear support for the reliability of his conclusions. If different SVAR models come to different conclusions on the same question, however, then the researcher needs to analyse his models more deeply. Obviously, only one of the compared models at most can be correct in such a case. At the core of the problem is the fact that SVAR models represent an approximation of reality. Of particular concern is whether a model aggregates a class of shocks at least approximately well. Faust and Leeper (1997) compare the bivariate model of Blanchard and Quah (1989; henceforth BQ) consisting of output and unemployment rate (YU model) with that of Bayoumi and Eichengreen (1993) consisting of output and inflation (YP model). Both studies aim at identifying supply and demand shocks in the economy. According to conventional wisdom, supply shocks should represent a convenient, balanced mixture of shocks to technological progress, depreciation rate, the labor supply, oil prices, etc. Demand shocks, in contrast, should stand for shocks changing preferences or tastes, monetary policy, fiscal policy, etc. Important is the ability of a small SVAR model to distinguish between these shocks as clearly as possible and to classify them correctly within the group of either supply or demand shocks. For the comparison made by Faust and Leeper (1997), however, a clear-cut solution is not available. It turns out that "the YP supply shock is more highly correlated with the YU demand shock (0.56) than with the YU supply shock (0.20)" which implies that "demand shocks in the YP model have a much smaller role in determining output over horizons of 2 to 5 years than in the YU model". Hence, the econometrician cannot obtain even an approximately clear answer to the question of which type of shocks drive the business cycle fluctuations in this example.

In this paper, we confront the findings of different SVAR models which differ in the 
way identification occurs as well as in terms of the variables included in order to gain more and higher quality information regarding the structural relationships in the economy. The investigation is closely related to the findings of Alexius and Carlsson (2001, 2005), who study the extent to which structural VAR models are capable of capturing the phenomena they are supposed to capture. They basically compare the technology shocks estimated using the bivariate Gali and the three-variable and six-variable KPSW models with two different technology measures that are computed using the production function approach: The first measure is the conventional Solow residual and the second is the refined Solow residual, which are estimated by Basu and Kimball (1997) inter alia. According to their findings, the technology measures of the three-variable and six-variable KPSW models do not reflect shocks to technology, but the technology measure resulting from the bivariate Gali model does. $^{2}$

Gali's bivariate model containing labor productivity and labor input is augmented with the nominal variables real balances, real interest rate and inflation in this study. ${ }^{3}$ It turns out that the extension of the basic model with nominal variables does not change the nature of the estimated technology shocks and allows a refinement of the nontechnology shocks of the bivariate model into three subgroups: labor-supply, real-interest-rate and inflation shocks. The identification of labor-supply shocks follows from using an approach similar to the one used by Shapiro and Watson (1988), and the real-interest-rate and inflation shocks are identified based on the KPSW identification scheme.

Although the augmentation of the bivariate Gali model with nominal variables does not change the nature of identified technology shocks much, the extension of the threevariable KPSW model with the same nominal variables leads to significant differences in the estimated technology measure. An interesting finding is that the technology shock of the three-variable KPSW model, the real-interest-rate shock of the six-variable KPSW model and the nontechnology shock of the bivariate Gali model are all moderately correlated. The

\footnotetext{
2 "The technology measure derived from the KPSW model mixes technology shocks with nontechnology phenomena. The Gali model, on the other hand, appears to be much more robust to nontechnology measures" according to Alexius and Carlsson (2005).

${ }^{3}$ Note that Gali augments the bivariate model with the same nominal variables, too. But a cointegration rank of 1 is assumed (and tested) in our paper in order to be consistent with the six-variable KPSW model, whereas Gali does not obtain this cointegration rank in his data set. See Section 3.2 for further explanation.
} 
estimated dynamic responses of output to these shocks in the corresponding models are accordingly qualitatively similar. There are, however, important quantitative differences.

The findings in Alexius and Carlsson (2005) underline the importance of the absence of a labor input variable in the three-variable KPSW model for identifying technology shocks. It is shown in this paper that the absence of the same variable in the six-variable KPSW model is also crucial for the biased estimation of technology shocks. Recall that labor input is used as a proxy for capacity utilization when computing the refined Solow residual. Containing it in a VAR that aims at identifiying technology shocks obviously helps avoid mixing technology and nontechnology phenomena. Therefore, the three-variable and sixvariable KPSW models are augmented with labor input in this paper, and we also adapt Gali's restriction for identifying technology shocks. This modification seems to correct the bias in the estimated technology shocks by a significant amount without affecting the nature of the real-interest-rate and inflation shocks.

The ultimate extension of the bivariate Gali model to a seven-variable KPSW model yields at least two advantages for an econometrician. The first advantage is that the dynamic effects of more structural shocks on more macroeconomic variables can be investigated without running the risk of obtaining a decreased estimation power due to a high number of variables since seven is a convenient number. Whereas the bivariate model allows us to classify the structural shocks as only technology and nontechnology, we can retain the technology shocks but refine the rest of the shocks further into labor-supply, real-interest-rate and inflation components. Furthermore, we can distinguish between transitory and permanent shocks due to the presence of cointegration.

The second advantage of extending a small model relates to the so-called omitted variables bias. If some necessary variables for the posed research question are not included in the estimated VAR, then at least two adverse affects are possible: First, the nature of estimated structural shocks and their dynamic effects may be distorted, as in the case of dropping the nominal variables and the related cointegration relationships from the six-variable KPSW model. Second, a small model may correctly identify the structural shocks, but it cannot scale their dynamic effects on the variables correctly. A related example follows from the study of Erceg et al. (2004), who carry out a simulation study to investigate the power of 
the Gali identification scheme. The authors generate artificial data sets based on different calibrated theoretical models which provide at the same time the "true" response of labor productivity and labor input to structural shocks. The caveat is that the nature of the data generation mechanism is very important for the success of the identification scheme; but the Gali identification scheme provides rather good estimations, in particular when the bivariate VAR is augmented with the consumption-to-output and investment-to-output ratios. Christiano et al. (2003) point to the problem of omitted variables by noting that "there is no a priori reason to expect that the answers generated from small bivariate systems will survive in larger dimensional systems." Similar to Erceg et al. (2004), they include the great ratios in addition to the federal funds rate and the rate of inflation in their estimated VAR.

The final contribution of this paper is to implement a variance decomposition approach discussed in Seymen (2007) for computing the role of structural shocks in the cyclical fluctuations of macroeconomic variables. We argue that this approach leads to healthier conclusions than the approaches used by Gali and KPSW. It turns out that technology shocks are the driving force of output fluctuations in none of the considered models. A surprising result is that supply (in particular labor-supply) shocks play the greatest role in the fluctuation of real balances, but not monetary shocks. Finally, the weight of the transitory vs. permanent shocks in the cycles depends very much on the model specification, but shocks with permanent effects play usually a more dominant role than shocks with only transitory effects.

The next section briefly reviews the two identification schemes considered throughout this paper, establishes a general notation for easily comparing the many model variations discussed and describes the data set. The basic models are presented and compared in Section 3. Section 4 is devoted to the modification of the basic models. Section 5 deals with the question of the sources of cyclical fluctuations. Section 6 provides concluding remarks.

\section{The Econometric Method and Data}

This section provides a brief review of the two SVAR identification schemes making use of long-run restrictions which are implemented throughout this paper. The first scheme follows from BQ for systems without cointegration and is applied by Gali. The second scheme 
is implemented by KPSW and is for cointegrated systems. Since the techniques are wellknown in the meanwhile, we describe them only briefly. The interested reader may refer to Lütkepohl (2005) or Blanchard and Quah (1989) and King et al. (1991).

\subsection{The BQ Identification Scheme}

Let $X_{t}$ be a vector of $K$ variables integrated of order one. ${ }^{4}$ The first differenced variables can be expressed as a distributed lag of white noise residuals $u_{t}$ with $E(L)$ being the lag polynomial containing the moving-average coefficient matrices, $L$ the lag operator and $\mu$ a $K \times 1$ vector of constants:

$$
\Delta X_{t}=\mu+E(L) u_{t}
$$

This is the so-called reduced form equation, which can be written in structural form as

$$
\Delta X_{t}=\mu+C(L) \varepsilon_{t}
$$

with $C(L):=E(L) C$ and $\varepsilon_{t}:=C^{-1} u_{t}$. There are infinite $C$ matrices of order $K \times K$ possible. In order to obtain a unique, economically meaningful structure from the reducedform equation (1), BQ and Gali impose the restriction that only the first structural shock in $\varepsilon_{t}$ can have an impact in the long run on the first variable in $X_{t} \cdot{ }^{5}$ Formally, the first element of $\Delta X_{t}$ can be written as

$$
\Delta X_{1, t}=\left[\begin{array}{llll}
C^{11}(L) & C^{12}(L) & \cdots & C^{1 K}(L)
\end{array}\right]\left[\begin{array}{c}
\varepsilon_{t}^{1} \\
\varepsilon_{t}^{2} \\
\vdots \\
\varepsilon_{t}^{K}
\end{array}\right]
$$

The identification restriction mentioned above corresponds to $C^{12}(1)=\cdots=C^{1 K}(1)=0$ with $C^{i j}(L)$ being the element of $C(L)$ corresponding to the $i^{\text {th }}$ variable and $j^{\text {th }}$ structural shock. The matrix of long-run multipliers $C(1)$ is assumed to be lower triangular in the BQ identification scheme.

\footnotetext{
${ }^{4}$ Note that not every variable in $X_{t}$ has to be integrated of order one for the identification scheme. This assumption is made here just for the ease of presentation.

${ }^{5}$ Moreover, the conventional atheoretical restriction that the covariance matrix of the structural shocks is an identity matrix is imposed.
} 


\subsection{The KPSW Identification Scheme}

The identification scheme developed by KPSW is applied to VAR systems with cointegrated variables. The matrix of long-run multipliers can be written then as

$$
\Gamma(1)=\left[\begin{array}{ll}
A & 0
\end{array}\right]
$$

where $\Gamma(1)$ is analogous to matrix $C(1)$ of the BQ identification scheme, $A$ is of order $K \times k$ and 0 is the zeros matrix of order $K \times r, k$ being the number of common stochastic trends and $r$ the cointegration rank. Furthermore, the matrix $A$ is assumed to have the form

$$
A=\hat{A} \Pi
$$

where $\hat{A}$ is a known $K \times k$ matrix and $\Pi$ is a $k \times k$ lower triangular matrix with ones on its diagonal. Hence, there are $r$ transitory and $k$ permanent shocks in the VAR model. ${ }^{6}$

KPSW construct the $\hat{A}$ matrix by using the parameters of the cointegrating equations which are estimated with the dynamic OLS technique discussed by Stock and Watson (1989). $\hat{A}$ can be determined by exploiting the fact that $\beta^{\prime} \hat{A}=0$ and $\beta^{\prime} \beta_{\perp}=0$ must be valid, where $\beta$ is the $K \times r$ matrix of cointegrating vectors and $\beta_{\perp}$ is its orthogonal with the order $K \times k$. Thus, one can choose

$$
\hat{A}=\beta_{\perp}
$$

This means that where the cointegrating vectors are estimated there are some free parameters in $\hat{A}$ which are not restricted other than $\beta^{\prime} \beta_{\perp}=0$. Notice that the number of unrestricted parameters in $\beta_{\perp}$ can be $r$ times $k$, that is, the cointegration rank times the number of stochastic trends in the VAR. ${ }^{7}$ This property is used in Section 4 in order to impose as few restrictions as possible for identification.

\subsection{Notation}

Table 1 identifies the variables in the models that are investigated in this paper. We point out that $\mathrm{G} 2 \mathrm{~V}$ is the only model here without cointegrating variables and where the

\footnotetext{
${ }^{6}$ Note that less than $k$ permanent shocks and/or more than $r$ transitory shocks is also possible in this identification scheme, but that is not assumed in this paper.

${ }^{7}$ This follows from the fact that the matrix $\beta^{\prime} \beta_{\perp}$ has the order $r \times k$.
} 
Table 1: Variables included in models considered in this study

\begin{tabular}{ll}
\hline \hline Model & Variables \\
\hline $\mathrm{G} 2 \mathrm{~V}:$ & $x, n$ \\
$\mathrm{G} 5 \mathrm{~V}:$ & $x, n, m-p, R-\Delta p, \Delta p$ \\
$\mathrm{~K} 3 \mathrm{~V}:$ & $y, c, i$ \\
$\mathrm{~K} 4 \mathrm{~V}:$ & $y, c, i, n$ \\
$\mathrm{~K} 6 \mathrm{~V}:$ & $y, c, i, m-p, R, \Delta p$ \\
$\mathrm{~K} 7 \mathrm{~V}:$ & $y, c, i, n, m-p, R, \Delta p$ \\
\hline
\end{tabular}

Notes: $\mathrm{G} i \mathrm{~V}$ and $\mathrm{K} i \mathrm{~V}$ represent $i$-variable Gali and KPSW models, respectively. $x$ is labor productivity, $n$ is labor input, $m-p$ is real balances, $R$ is the nominal interest rate, $\Delta p$ is inflation, $y$ is output, $c$ is consumption, $i$ is investment.

Table 2: Estimated shocks in models considered in this study

\begin{tabular}{ll}
\hline \hline Model & Identified Shocks \\
\hline G2V: & Technology, nontechnology \\
G5V: & Technology, labor-supply, inflation, real-interest-rate \\
K3V: & Technology \\
K4V: & Technology, labor-supply \\
K6V: & Technology, inflation, real-interest-rate \\
K7V: & Technology, labor-supply, inflation, real-interest-rate \\
\hline
\end{tabular}

Note: See Table 1 for abbreviations.

BQ identification scheme is implemented. In all other models, the cointegration rank is at least 1 and the structural shocks are estimated based on the KPSW scheme. The number of shocks identified in these models is therefore less than the number of the variables, as the transitory shocks are not further analyzed. The structural shocks identified in the models are given in Table 2.

\subsection{Data and Model Specification}

Original KPSW data is used for all common variables in this paper. The labor input measure is the total hours worked used by Gali. All variables except the nominal interest rate are in logs. The sample period 1954:1 to 1988:4 is common to both the KPSW and the 
Gali models and is chosen in order to guarantee comparability with the original papers by Gali and KPSW. Moreover, it coincides with the one considered by Alexius and Carlsson (2001, 2005), so that their conclusions become directly relevant for the arguments provided in Section 4 of this paper.

Gali estimates his model with four lags and KPSW with eight lags. We set the lag number to eight ${ }^{8}$ in all estimated models for the sake of comparison.

\section{The Basic Models}

In this section, we document the nature of the basic Gali and KPSW models and investigate the relationships among them. Throughout the rest of the paper, we often use the expression "the business cycle component of a variable with respect to (henceforth w.r.t.) a certain structural shock". This means that all other shocks except this particular shock are set to 0 in the SVAR when the historical time series are computed using the estimated model and the outcome is HP-filtered. ${ }^{9}$

\section{1. $K P S W(1991)$}

The Three-Variable Model KPSW estimate three-variable and six-variable SVARs with long-run restrictions. The three-variable model consists of output $(y)$, consumption $(c)$ and investment $(i)$. The cointegration rank is 2 according to the Johansen test in this model. KPSW test whether the great ratios, $c-y$ and $i-y$, are stationary, and nonstationarity of these ratios is rejected. A cointegration rank of 2 indicates that there is one structural shock with a permanent effect on the variables. Given their finding of the stationarity of the great ratios, KPSW argue that the permanent shock can affect the levels of the variables in the long run but not the great ratios. They call the shock with the permanent effect a balancedgrowth shock and argue that it is supposed to be a measure of technological innovations. ${ }^{10}$

\footnotetext{
${ }^{8}$ Note that eight lags in the models estimated with once-differenced variables (with or without cointegration) means nine lags when a model is written in level.

${ }^{9}$ Note that this is not the only way to compute the historical business cycle components of a variable, but one of the possibilities. Since Gali employs this type of a definition, we do the same for the sake of comparability. Nevertheless, the reader should keep in mind that other type of historical decompositions, e.g. the Beveridge-Nelson decomposition, could also be used. See Seymen (2007) on this issue.

${ }^{10}$ We therefore write "technology" instead of "balanced-growth" for K3V in the corresponding cell in Table 2 .
} 
Note that the nonzero part of the matrix of long-run multipliers $\Gamma$ (1) reads

$$
A=\left[\begin{array}{l}
1 \\
1 \\
1
\end{array}\right]\left[\begin{array}{l}
1
\end{array}\right]
$$

with

$$
\beta^{\prime}=\left[\begin{array}{ccc}
1 & -1 & 0 \\
1 & 0 & -1
\end{array}\right]
$$

being orthogonal to matrix $A$.

The Six-Variable Model The six-variable model is an augmented version of the threevariable model with real balances $(m-p)$, nominal interest rate $(R)$ and inflation $(\Delta p)$. The tests and the theoretical arguments of KPSW point to a cointegration rank of 3 in the augmented model. The three cointegrating relationships are assessed to be the moneydemand equation,

$$
m-p=\beta_{y} y-\beta_{R} R
$$

and the relationships between the real ratios and the real interest rate,

$$
c-y=\phi_{1}(R-\Delta p)
$$

and

$$
i-y=\phi_{2}(R-\Delta p)
$$

with $\beta_{y}, \beta_{R}, \phi_{1}$ and $\phi_{2}$ being coefficients estimated using the dynamic OLS technique. The $A$ matrix in the matrix of long-run multipliers $\Gamma(1)$ is accordingly written as

$$
A=\left[\begin{array}{ccc}
1 & 0 & 0 \\
1 & 0 & \phi_{1} \\
1 & 0 & \phi_{2} \\
\beta_{y} & -\beta_{R} & -\beta_{R} \\
0 & 1 & 1 \\
0 & 1 & 0
\end{array}\right]\left[\begin{array}{ccc}
1 & 0 & 0 \\
\pi_{21} & 1 & 0 \\
\pi_{31} & \pi_{32} & 1
\end{array}\right]
$$


where $\pi_{i j}$ are unrestricted coefficients. Note that the order of the variables in the model is $y, c, i, m-p, R$ and $\Delta p$, and the matrix $\hat{A}$ (see Section 2) in (11) is written such that the cointegrating relationships hold. Furthermore, $\hat{A}$ is orthogonal to the cointegrating vectors. ${ }^{11}$

The first shock is named a real-balanced-growth (technology) shock, which leads to (approximately) a unit long-run increase in $y, c$ and $i .{ }^{12}$ Hence, the great ratios are (virtually) not affected in the long run when only this shock occurs in the economy. The second permanent shock is the only shock with a unit long-run effect on the inflation rate according to (11) and is therefore called an inflation shock. ${ }^{13}$ The last permanent shock can affect the real ratios according to the cointegrating relationships and it has a unit effect on the real interest rate in the long run. It is hence called a real-interest-rate shock. Put it differently, this last shock has no long-run effect on output, but its effect on consumption and investment is measured by $\phi_{1}$ and $\phi_{2}$, respectively. Hence, a permanent change in the real interest rate leads to permanent changes in the great ratios. ${ }^{14}$

Comparison of Three-Variable and Six-Variable Models The three-variable and sixvariable models have the three variables $y, c$ and $i$ and one structural shock, the technology shock, in common. This enables us to compare i) the dynamic effects of a technology shock on $y, c$ and $i$; ii) the identified technology shocks of both models and iii) the historical components of $y, c$ and $i$ w.r.t. the realized technology shocks in the past. These factors are further described as follows:

i) A comparison of Figures 2 and 4 in KPSW clearly shows that the estimated dynamic effects of a technology shock change substantially when nominal variables are added to the

${ }^{11}$ In particular, one can write

$$
\beta^{\prime}=\left[\begin{array}{cccccc}
\beta_{y} & 0 & 0 & -1 & -\beta_{R} & 0 \\
1 & -1 & 0 & 0 & \phi_{1} & -\phi_{1} \\
1 & 0 & -1 & 0 & \phi_{2} & -\phi_{2}
\end{array}\right] .
$$

It is easy to verify then that $\beta \hat{A}=0$.

${ }^{12}$ We write here "approximately", since the long-run effect of this shock on $y, c$ and $i$ respectively is $1,1+\phi_{1} \pi_{21}$ and $1+\phi_{2} \pi_{31}$ where $\phi_{1} \pi_{21}$ and $\phi_{2} \pi_{31}$ are very small.

${ }^{13}$ Technology shocks could also affect the inflation rate in the long run, but only marginally.

${ }^{14}$ This has also a clear economic interpretation: Long-run changes in the real-interest-rate affect long-run consumption-saving decisions. 
Table 3: Correlations among estimated shocks of K3V and K6V

\begin{tabular}{cccc}
\hline \hline & K6V,tech & K6V,inf & K6V,rir \\
\hline K3V,tech & 0.21 & -0.17 & 0.55 \\
& $(0.09)$ & $(0.07)$ & $(0.06)$ \\
\hline
\end{tabular}

Notes: Standard error in parenthesis. tech is technology, inf is inflation, rir is real-interest-rate. See Table 1 for further abbreviations.

three-variable model.

ii) The finding in i) readily hints that there is a certain amount of inconsistency between the estimations of the models. If there were no omitted variable bias and the identification scheme were good enough, then it would be expected that the estimated technology measures of both models were highly correlated while the technology shock of the three-variable model were orthogonal to the inflation shock and real-interest-rate shock of the six-variable model. Table 3, however, shows that such a consistency does not exist. In particular, the technology shocks of both models show a statistically significant but weak correlation. Moreover, the technology shock of the three-variable model is correlated with the real-interest-rate shock of the six-variable model with a correlation coefficient of 0.55 .

iii) It is clear that augmenting the three-variable model leads to important changes in the results with respect to the identified technology shocks. The business cycle components of output, consumption, and investment w.r.t. the technology shock in both models are illustrated in Figure 1. The corresponding correlation coefficients are merely 0.26, 0.37 and 0.25 for output, consumption and investment technology components, respectively. Moreover, the volatility of the output and consumption components is remarkably higher in the three-variable model. It can therefore be concluded that adding nominal variables to the three-variable model leads to substantial changes in terms of identified technology shocks and the corresponding dynamic multipliers. That is not so surprising, however, given the reported findings in ii) that the technology components of the variables in the three-variable model have a higher correlation with the real-interest-rate components of the correspond- 
ing variables illustrated in Figure 2. The computed correlation coefficients which are the counterpart of the coefficients $0.26,0.37$ and 0.25 are $0.45,0.33$ and 0.41 , respectively.
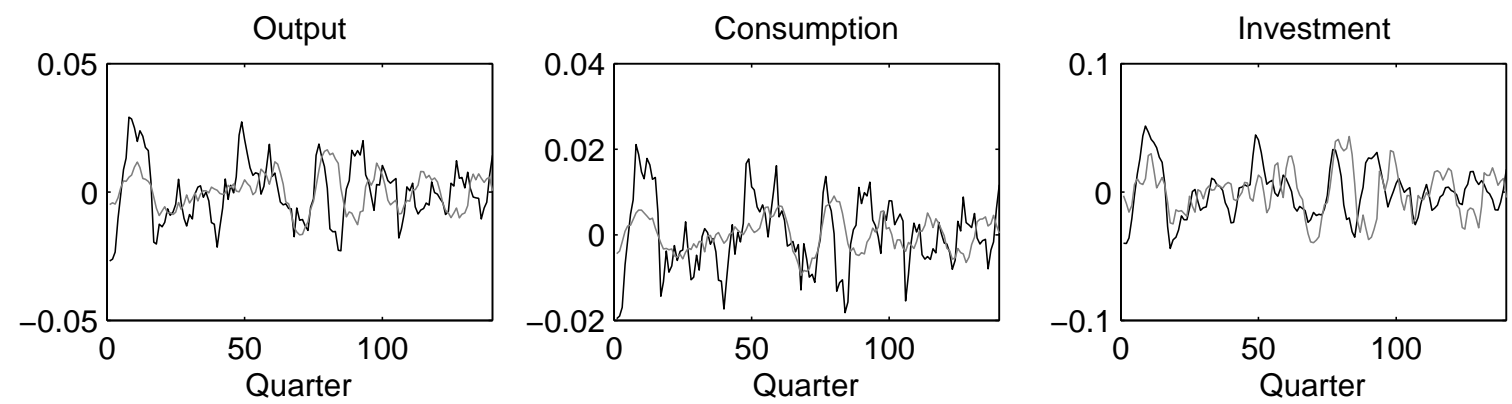

Figure 1: Technology components of output, consumption and investment in three-variable (black) and six-variable (grey) KPSW models
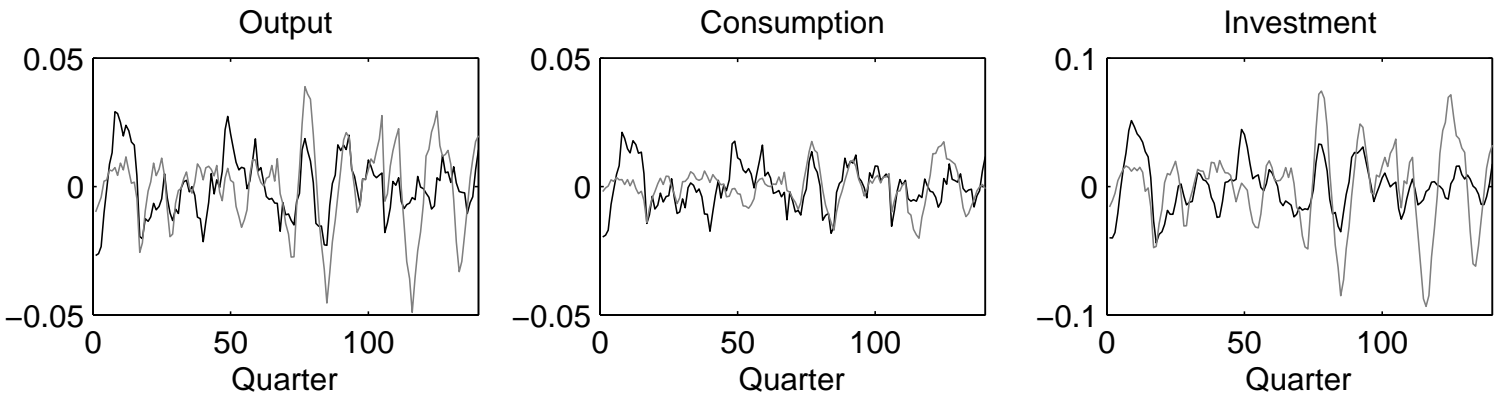

Figure 2: Technology (black) vs. real-interest-rate (grey) components of output, consumption and investment in three-variable (black) and six-variable (grey) KPSW models

In order to understand the statistical reason behind this last finding, it makes sense to confront the dynamic responses to a technology shock in K3V with the dynamic responses to a real-interest-rate shock in $\mathrm{K} 6 \mathrm{~V}$, as is done in Figure 3. The impulse response functions follow indeed different paths. The relatively higher correlations between the technology components of output and investment of K3V and the relevant real-interest-rate components of $\mathrm{K} 6 \mathrm{~V}$ is obviously an artifact of the similarity of the impulse response functions for the first four quarters.

In summary, it can be said that the extension of the three-variable model with nominal variables leads to important differences in the estimated dynamics. Moreover, a strong mingling of estimated structural shocks can be diagnosed. Nevertheless, although this finding 

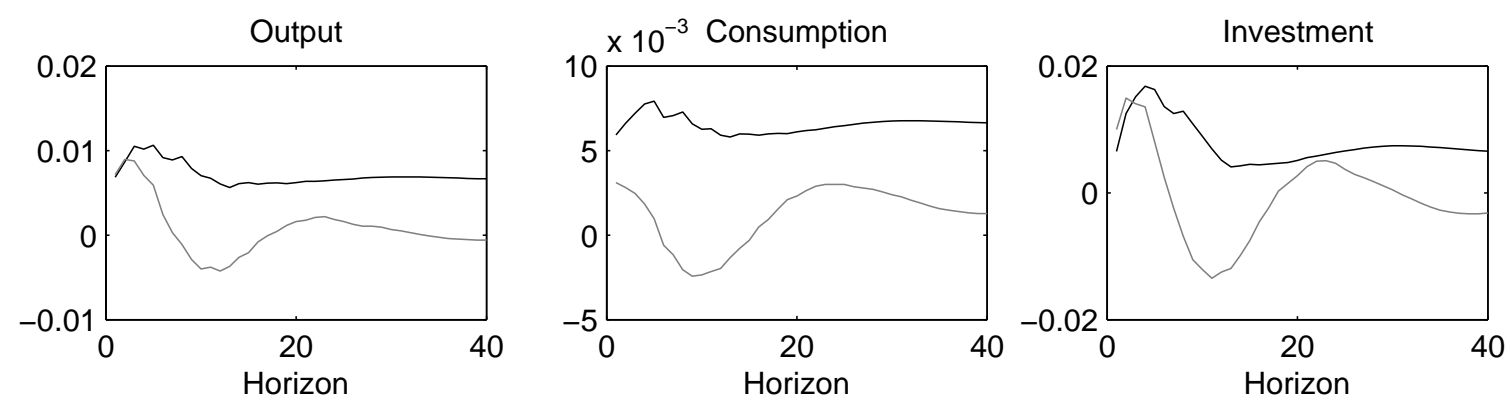

Figure 3: Impulse response functions of output, consumption and investment w.r.t. technology (black) vs. real-interest-rate (grey) shocks in three-variable (black) and six-variable (grey) KPSW models

points to an omitted variables bias for the small model, there is no guarantee yet that the six-variable model is not vulnerable to such a critique. We turn to this issue in Section 4.

\section{2. $\operatorname{Gali}(1999)$}

The Bivariate Model The basic model in Gali (1999) is a bivariate VAR comprising labor productivity $(x)$ and labor input $(n)$. Both variables are nonstationary according to the Augmented-Dickey-Fuller (ADF) test but are not cointegrated. The crucial identifying restriction is that the technology shock is the only structural shock with an impact on labor productivity in the long run. Alexius and Carlsson (2001, 2005) report that this assumption is a credible way of identifying technology shocks.

The Five-Variable Model It turns out that augmenting the bivariate model with the same nominal variables as in the six-variable KPSW model does not change the nature of the identified technology shocks and the corresponding dynamic multipliers very much. Gali readily shows with a similar five-variable model including real balances, real interest rate and inflation that the response of output, labor input and labor productivity to a technology shock is not affected much by such an extension. He reports that tests point to no cointegration in the five-variable model. Note, however, that he works with a different sample period and different definitions of some of the variables in his paper. In particular, inflation is computed using the CPI by Gali, but the GDP deflator is used when computing inflation 
in this paper following KPSW. We obtain a cointegration rank of 1 in the five-variable Gali model according to the Johansen test using the data set considered in this paper. This finding is indeed in line with the six-variable KPSW model where one of the cointegrating relationships is the long-run money-demand equation. Since the five-variable model contains the same variables that exist in the money-demand relationship, i.e., output, real balances and nominal interest rate, it should contain at least this cointegration relationship. Following this reasoning, we construct the matrix of long-run multipliers for the five-variable model as follows:

$$
A=\left[\begin{array}{cccc}
1 & 0 & 0 & 0 \\
1 & 1 & 0 & 0 \\
* & * & * & * \\
1 & 1 & 1 & 0 \\
1 & 1 & 1 & 1
\end{array}\right]\left[\begin{array}{cccc}
1 & 0 & 0 & 0 \\
\pi_{21} & 1 & 0 & 0 \\
\pi_{31} & \pi_{32} & 1 & 0 \\
\pi_{41} & \pi_{42} & \pi_{43} & 1
\end{array}\right] .
$$

Given that $r=1$ and $k=4$, we leave four elements of the matrix $\hat{A}$ unrestricted as mentioned in Section 2.2. These unrestricted elements are determined based on the information provided by the only cointegrating vector, which reads for this model ${ }^{15}$

$$
\beta^{\prime}=\left[\begin{array}{lllll}
\beta_{y} & \beta_{y} & -1 & -\beta_{R} & -\beta_{R}
\end{array}\right] .
$$

A cointegration rank of 1 implies that the five-variable model contains four permanent shocks. The first of these shocks is named technology in the spirit of Gali. We call the second shock a labor-supply shock, since it is the only shock together with technology that has a long-run effect on labor input. ${ }^{16}$ The third shock is a real-interest-rate shock in the same sense as in KPSW: It has a unit effect on the real interest rate in the long run and it

\footnotetext{
${ }^{15}$ Recall that $X_{t}=\left[\begin{array}{lllll}x_{t} & n_{t} & m_{t}-p_{t} & R_{t}-\Delta p_{t} & \Delta p_{t}\end{array}\right] '$ with $x_{t}=y_{t}-n_{t}$ so that (8) holds. Note, furthermore, that KPSW could have left two elements of the matrix $\hat{A}$ unrestricted in the three-variable model since $r=2$ and $k=1$ in the three-variable VAR. Similarly, nine elements of $\hat{A}$ could be left unrestricted in the six-variable model since $r=3$ and $k=3$. But they do not prefer this route in their study, which is probably not decisive for the conclusions reached.

${ }^{16}$ The augmented Gali model is closely related to the model studied by Shapiro and Watson (1988), considered also in Alexius and Carlsson (2005), which is a four-variable VAR with labor input, output, inflation and real interest rate. Shapiro and Watson (1988) assume that labor input is affected by only technological disturbances in the long run, which differs in the identification scheme of Gali (1999). Labor productivity is, in contrast, affected by both technological and labor-supply disturbances. All of these shocks can affect inflation in the long run. Finally, the augmented Gali model includes real balances in the VAR system, whereas the Shapiro-Watson model does not.
} 
is allowed to affect the real balances and the inflation rate as well, but not the output or the labor input. ${ }^{17}$ Finally, the last shock is called the inflation shock, with a unit effect on the inflation rate in the long run; it can furthermore have an impact on real balances, but the other variables are not affected by this shock in the long run like in $\mathrm{K} 6 \mathrm{~V}$.

\section{Comparison of Two-Variable and Five-Variable Models}

i) Figure 4 shows the dynamic response of labor productivity, labor input and output to a technology shock in two-variable and five-variable Gali models. The difference is, as can be easily established, not great even in the long run.
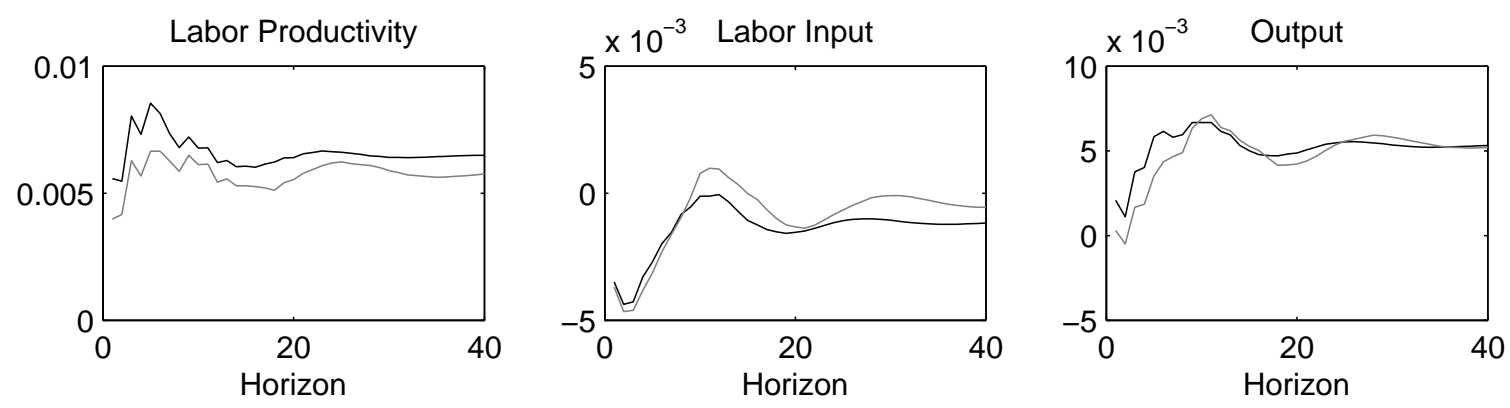

Figure 4: Impulse response functions of labor productivity, labor input and output w.r.t. a technology shock in two-variable (black) and five-variable (grey) Gali models

ii) The correlation structure of the structural shocks of bivariate and five-variable models in Table 4 does not contain any inconsistencies. The technology measures of both models are statistically uncorrelated with each other's nontechnology measures. But they are highly correlated between each other, in particular, the estimated nontechnology shock of the bivariate model seems to be related to the inflation and the real-interest-rate measures of the five-variable model, whereas the labor-supply shock does not find a reflection in the bivariate model. Overall, it can be concluded that the bias that exists in the KPSW framework w.r.t. the inclusion of nominal variables in the VAR does not exist in the Gali framework.

\footnotetext{
${ }^{17}$ Note that the real-interest-rate shock can affect the great ratios in $\mathrm{K} 6 \mathrm{~V}$, but great ratios are not included in this model.
} 
Table 4: Correlations among estimated shocks of G2V and G5V

\begin{tabular}{ccccc}
\hline \hline & G5V,tech & G5V,ls & G5V,inf & G5V,rir \\
\hline G2V,tech & 0.84 & -0.05 & 0.05 & -0.07 \\
& $(0.03)$ & $(0.08)$ & $(0.08)$ & $(0.08)$ \\
G2V,nontech & -0.14 & 0.16 & 0.40 & 0.62 \\
& $(0.08)$ & $(0.09)$ & $(0.06)$ & $(0.07)$ \\
\hline
\end{tabular}

Notes: Standard error in parenthesis. nontech is nontechnology, ls is labor-supply. See Tables 1 and 3 for further abbreviations.

iii) The technology components of labor productivity, labor input and output, i.e., the common variables of the bivariate and five-variable models, are illustrated in Figure 5. As the findings in i) and ii) already hint at, the correlations between these components are very high, namely $0.80,0.80$ and 0.72 , respectively.
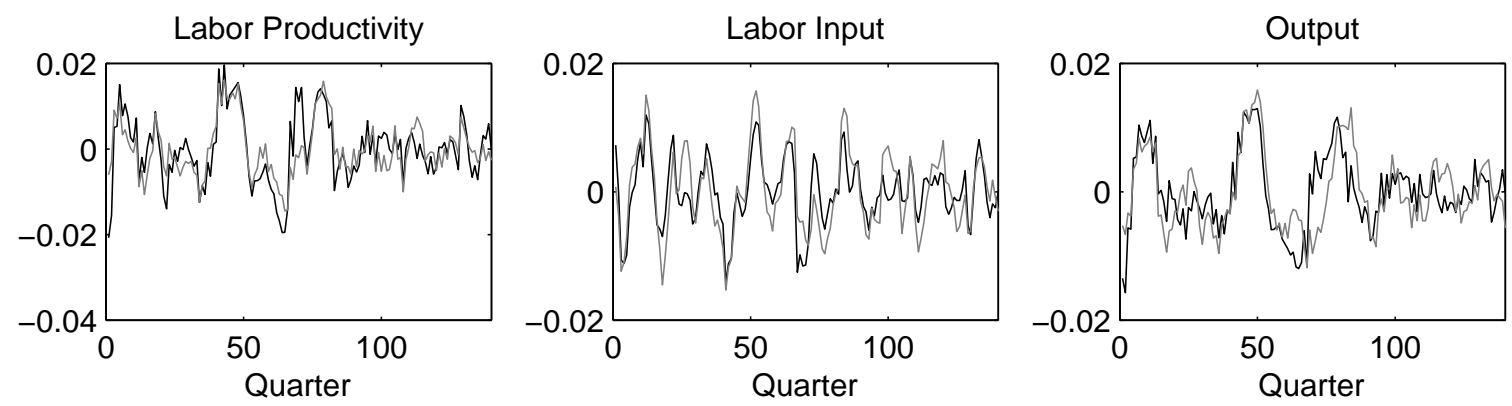

Figure 5: Technology components of labor productivity, labor input and output in twovariable (black) and five-variable (grey) Gali models

\subsection{Comparison of the Basic Models}

Technology Shocks vs. Technology Shocks A comparison of the basic models starts naturally with the comparison of estimated technology shocks, which has already been partly carried out above. Alexius and Carlsson (2001, 2005) investigate the properties of the technology shocks of the bivariate Gali and the three-variable and six-variable KPSW models. Two aspects in which the identification of technology shocks in Gali and KPSW frameworks differs should be emphasized. The first aspect is that the identifying restrictions are different. 
Table 5: Correlations among estimated technology shocks

\begin{tabular}{cccccc}
\hline \hline Model & K3V & K4V & K6V & K7V & G2V \\
\hline K4V & -0.09 & 1 & & & \\
& $(0.09)$ & & & & \\
K6V & 0.21 & 0.12 & 1 & & \\
& $(0.09)$ & $(0.08)$ & & & \\
K7V & -0.12 & 0.64 & 0.38 & 1 & \\
& $(0.08)$ & $(0.05)$ & $(0.06)$ & & \\
G2V & 0.14 & 0.88 & 0.17 & 0.63 & 1 \\
& $(0.09)$ & $(0.02)$ & $(0.09)$ & $(0.05)$ & \\
G5V & 0.01 & 0.75 & 0.35 & 0.76 & 0.84 \\
& $(0.08)$ & $(0.04)$ & $(0.07)$ & $(0.03)$ & $(0.03)$ \\
\hline
\end{tabular}

Notes: Standard error in parenthesis. See Table 1 for abbreviations.

The Gali framework assumes as the crucial restriction that a technology shock cannot affect labor productivity in the long run, whereas the KPSW framework identifies a technology shock as one that affects the levels of macroeconomic variables but not the great ratios in the long run. The second aspect is that consumption, investment and the great ratios are absent in the Gali framework, while labor input and labor productivity are absent in the KPSW framework. The correlation coefficients reported in Table 5 show that the technology measures of the Gali framework are at most weakly correlated with the technology measures of the KPSW framework.

G2V vs. K3V and K6V We confront next the estimated technology and nontechnology shocks of the basic models. Table 6 shows that whereas the technology measures of G2V and $\mathrm{K} 3 \mathrm{~V}$ are not compatible with each other, the technology measure of K3V is related to the nontechnology measure of G2V. Given the findings of Alexius and Carlsson (2005), the bivariate Gali technology and nontechnology measures are assumed to be the correct ones in this study. Hence, we conclude that K3V mingles technology and nontechnology phenomena. The estimated technology shock series of G2V is, however, not related to any of the identified shocks of K6V, although we can establish a strong relationship between the nontechnology shock of G2V and the real-interest-rate shock of K6V. Hence, it is concluded 
Table 6: Correlations among estimated shocks

\begin{tabular}{cccc}
\hline \hline Model & K3V,tech & K4V,tech & K4V,ls \\
\hline G2V,tech & 0.14 & 0.88 & 0.22 \\
& $(0.09)$ & $(0.02)$ & $(0.08)$ \\
G2V,nontech & 0.57 & -0.03 & 0.59 \\
& $(0.05)$ & $(0.08)$ & $(0.05)$ \\
\hline
\end{tabular}

\begin{tabular}{cccccccc}
\hline \hline Model & K6V,tech & K6V,inf & K6V,rir & K7V,tech & K7V,ls & K7V,inf & K7V,rir \\
\hline G2V,tech & 0.17 & -0.09 & 0.17 & 0.63 & -0.03 & 0.08 & 0.27 \\
& $(0.09)$ & $(0.09)$ & $(0.08)$ & $(0.05)$ & $(0.08)$ & $(0.09)$ & $(0.07)$ \\
G2V,nontech & 0.01 & -0.03 & 0.61 & -0.40 & 0.22 & 0.03 & 0.52 \\
& $(0.09)$ & $(0.08)$ & $(0.05)$ & $(0.08)$ & $(0.09)$ & $(0.08)$ & $(0.06)$ \\
\hline
\end{tabular}

Notes: Standard error in parenthesis. See Tables 1 and 4 for abbreviations.

that what is presented as a technology shock in $\mathrm{K} 3 \mathrm{~V}$ and a real-interest-rate shock in $\mathrm{K} 6 \mathrm{~V}$ contain substantial nontechnology and/or demand elements.

Given these findings, it is interesting to look at the dynamic response of output to nontechnology, technology and real-interest-rate shocks in G2V, K3V and K6V, respectively. These are shown in Figure 6. Although there are important quantitative discrepancies among the dynamic responses of output to the different structural shocks, they follow qualitatively similar patterns. In particular, the dynamic response of output to a nontechnology shock in G2V follows the response to a real-interest-rate shock in K6V very closely. These dynamic responses strengthen our interpretation given in the previous paragraph.

An interesting point is that the $\mathrm{K} 3 \mathrm{~V}$ technology, the $\mathrm{K} 6 \mathrm{~V}$ real-interest-rate and the G2V nontechnology shocks are reported to be the main driving force behind the cyclical fluctuations of output in the corresponding papers. Hence, it can be argued that, taking into account the bias in the KPSW identification framework, the same finding is reached as by Gali: Nontechnology shocks play a more important role than technology shocks in the business cycle fluctuations of output. We investigate the robustness of this conclusion in Section 5 of this paper. 


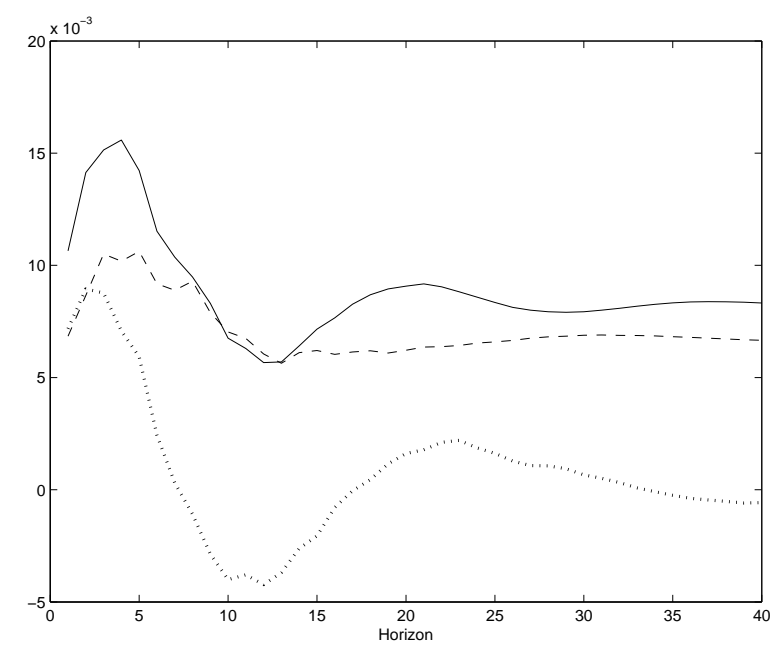

Figure 6: Dynamic response of output to a nontechnology shock in G2V (solid), to a technology shock in K3V (dashed), to a real-interest-rate shock in K6V (dotted)

The Role of Labor Supply Shocks Alexius and Carlsson (2005) find that "labor supply shocks drive a wedge between the [three-variable] KPSW and [bivariate] Gali measures of technology". This interpretation is also valid for a comparison of the identified shocks of K6V and G5V. The correlation coefficients reported in Table 7 show that the K6V technology shock has a much higher correlation with the G5V labor-supply shock than with the G5V technology measure. The real-interest-rate and inflation shocks of the two models are, however, not clearly distinguishable from each other, although they are not related to the technology and labor-supply shocks. Finally, even though the G5V labor-supply and the $\mathrm{K} 6 \mathrm{~V}$ inflation as well as the G5V technology and the K6V real-interest-rate shocks are significantly correlated with each other, the correlation is rather weak. This means that all of these shocks are not statistically but approximately orthogonal to each other (as they should be).

G5V vs. K3V Among all the models considered throughout this paper, G5V and K3V are the ones with the least common properties. They only share output as a common variable and the technology shock as a common identified shock. This is reflected in the weak reported correlations in Table 7 . The technology measures are even virtually orthogonal to each other, whereas the real-interest-rate and inflation measures of G5V are related weakly 
Table 7: Correlations among estimated shocks

\begin{tabular}{ccccc}
\hline \hline Model & G5V,tech & G5V,ls & G5V,inf & G5V,rir \\
\hline K3V,tech & 0.01 & 0.12 & 0.32 & 0.33 \\
& $(0.08)$ & $(0.08)$ & $(0.07)$ & $(0.08)$ \\
K6V,tech & 0.35 & 0.71 & -0.03 & 0.02 \\
& $(0.07)$ & $(0.04)$ & $(0.10)$ & $(0.09)$ \\
K6V,inf & -0.09 & 0.21 & 0.63 & -0.46 \\
& $(0.09)$ & $(0.08)$ & $(0.05)$ & $(0.07)$ \\
K6V,rir & 0.19 & -0.11 & 0.56 & 0.69 \\
& $(0.08)$ & $(0.08)$ & $(0.05)$ & $(0.04)$ \\
\hline
\end{tabular}

Notes: Standard error in parenthesis. See Tables 1 and 4 for abbreviations.

to the technology measure of K3V.

\section{Modifying the Basic Models}

The biased KPSW framework is modified and the effects of this modification are reported in this section. The bias is in particular due to the lack of the labor input variable in K3V and $\mathrm{K} 6 \mathrm{~V}$ and the particular restriction for the identification of technology shocks. Therefore, the modification is carried out by adding labor input to three-variable and six-variable KPSW models and adapting the approach of Gali for identifying technology shocks.

\subsection{The Four-Variable Model}

Labor input is added as the fourth variable to the three-variable KPSW model. Assuming (and testing) a cointegration rank of 2, there are two stochastic trends in $\mathrm{K} 4 \mathrm{~V}$. The first shock is named technology as before, and the second permanent shock is a labor-supply shock. The part of the matrix of long-run multipliers corresponding to the permanent shocks reads

$$
A=\left[\begin{array}{rr}
1 & 1 \\
* & * \\
* & * \\
-1 & 1
\end{array}\right]\left[\begin{array}{cc}
1 & 0 \\
\pi_{21} & 1
\end{array}\right]
$$


where the entries with an asterisk mean that these parameters are not restricted. Note that such a matrix of long-run multipliers is in line with the crucial Gali identification restriction: Technology shock is the only one that can affect the labor productivity in the long run. ${ }^{18}$ The matrix of cointegrating vectors in $\mathrm{K} 4 \mathrm{~V}$ is an extension of the specification used in $\mathrm{K} 3 \mathrm{~V}$ by KPSW:

$$
\beta^{\prime}=\left[\begin{array}{cccc}
1 & -1 & 0 & 0 \\
1 & 0 & -1 & 0
\end{array}\right]
$$

\subsection{The Seven-Variable Model}

Similarly, K6V is augmented with labor input as the fourth variable in the VAR. The part of the matrix of long-run multipliers corresponding to the permanent shocks in K7V reads then

$$
A=\left[\begin{array}{cccc}
1 & 1 & 0 & 0 \\
1 & * & * & * \\
* & 1 & * & * \\
-1 & 1 & 0 & 0 \\
\beta_{y} & 1 & -\beta_{R} & * \\
* & * & * & 1 \\
* & * & 1 & 0
\end{array}\right]\left[\begin{array}{cccc}
1 & 0 & 0 & 0 \\
\pi_{21} & 1 & 0 & 0 \\
\pi_{31} & \pi_{32} & 1 & 0 \\
\pi_{41} & \pi_{42} & \pi_{43} & 1
\end{array}\right] .
$$

The matrix of cointegrating vectors is changed in the same way as for $\mathrm{K} 3 \mathrm{~V}$; that is, a column of zeros is added that corresponds to the labor input variable:

$$
\beta^{\prime}=\left[\begin{array}{ccccccc}
\beta_{y} & 0 & 0 & 0 & -1 & -\beta_{R} & 0 \\
1 & -1 & 0 & 0 & 0 & \phi_{1} & -\phi_{1} \\
1 & 0 & -1 & 0 & 0 & \phi_{2} & -\phi_{2}
\end{array}\right]
$$

$\mathrm{K} 4 \mathrm{~V}$ and $\mathrm{K} 7 \mathrm{~V}$ are simple extensions of the bivariate and five-variable Gali models, respectively. They assume the same restriction for the identification of the technology measure,

\footnotetext{
${ }^{18}$ The $A$ matrix implies that the long-run effect of the technology shock on output and labor input is $1+\pi_{21}$ and $-1+\pi_{21}$, respectively. Thus, the labor productivity is affected by technology shocks by 2 units in the long run. Note that $\pi_{21}$ is an unrestricted parameter. Moreover, the labor-supply shock does not affect the labor productivity in the long run in line with the G2V identification scheme.
} 
but include the balanced-growth property as well. It could be argued that $\mathrm{K} 4 \mathrm{~V}$ and $\mathrm{K} 7 \mathrm{~V}$ are superior to the respective Gali models in the identification of structural shocks as they use more information. Gali models are just a subset of them.

\subsection{Results}

KPSW Models Table 8 shows the bias in the KPSW models pointed out by Alexius and Carlsson (2005). When the labor-supply variable is added to K3V and K6V and technology and labor-supply shocks are separated, it is observed that what is identified as the technology measure in $\mathrm{K} 3 \mathrm{~V}$ and $\mathrm{K} 6 \mathrm{~V}$ is spoiled with a labor-supply component. The correlation between the technology shock of $\mathrm{K} 3 \mathrm{~V}$ and the labor-supply shock of $\mathrm{K} 4 \mathrm{~V}$ is 0.97 , whereas the correlation of technology shocks of both models is statistically not different from 0 . The picture is similar for the comparison of the $\mathrm{K} 6 \mathrm{~V}$ and $\mathrm{K} 7 \mathrm{~V}$ technology measures, although these are more strongly correlated than the K3V and K4V measures. ${ }^{19}$ Moreover, the character of inflation and real-interest-rate shocks is independent of whether the labor-supply variable is included in the KPSW framework and the Gali identification restriction for the technology shocks is implemented.

It is striking that the labor-supply measures of $\mathrm{K} 4 \mathrm{~V}$ and $\mathrm{K} 7 \mathrm{~V}$ are not strongly correlated. In addition, a mingling of structural shocks by at least one of these models also occurs. In particular, the K7V real-interest-rate shock is weakly but highly significantly related to the K4V technology measure with a correlation coefficient of 0.24. Furthermore, the estimated $\mathrm{K} 4 \mathrm{~V}$ labor-supply measure is more closely related to the $\mathrm{K} 7 \mathrm{~V}$ real-interest-rate measure than to the K7V labor-supply measure. This can be interpreted as the indication of an omitted variables problem in $\mathrm{K} 4 \mathrm{~V}$ due to the lack of the nominal variables.

Technology Shocks Assuming that Gali technology and nontechnology measures provide a good approximation of the true measures, it is obtained that including the labor input variable in KPSW models corrects the bias regarding the identification of technology shocks.

\footnotetext{
${ }^{19}$ A theoretical explanation to this finding can be found in a simulation study by Erceg et al. (2004), who obtain that estimated technology shocks identified using the Gali scheme could be "contaminated by other shocks and in particular by the labor-supply shock" where the data generating mechanism is a standard RBC model with some nominal rigidities.
} 
Table 8: Correlations among identified shocks of KPSW models

\begin{tabular}{|c|c|c|c|c|c|c|}
\hline Model & K4V,tech & $\mathrm{K} 4 \mathrm{~V}$,ls & K7V,tech & $\mathrm{K} 7 \mathrm{~V}, \mathrm{ls}$ & K7V,inf & K7V,rir \\
\hline K3V,tech & $\begin{array}{l}-0.09 \\
(0.09)\end{array}$ & $\begin{array}{c}0.97 \\
(0.00)\end{array}$ & $\begin{array}{l}-0.12 \\
(0.09)\end{array}$ & $\begin{array}{c}0.40 \\
(0.07)\end{array}$ & $\begin{array}{l}-0.09 \\
(0.08)\end{array}$ & $\begin{array}{c}0.49 \\
(0.06)\end{array}$ \\
\hline Model & K4V,tech & $\overline{\mathrm{K} 4 \mathrm{~V}, \mathrm{ls}}$ & "K7V,tech & $\overline{\mathrm{K} 7 \mathrm{~V}, \mathrm{ls}}$ & K7V,inf & "K7V,rir \\
\hline K6V,tech & $\begin{array}{c}0.12 \\
(0.08)\end{array}$ & $\begin{array}{c}0.19 \\
(0.09)\end{array}$ & $\begin{array}{c}0.38 \\
(0.06)\end{array}$ & $\begin{array}{c}0.80 \\
(0.03)\end{array}$ & $\begin{array}{c}0.06 \\
(0.09)\end{array}$ & $\begin{array}{c}0.12 \\
(0.08)\end{array}$ \\
\hline K6V,inf & $\begin{array}{l}-0.05 \\
(0.09)\end{array}$ & $\begin{array}{l}-0.17 \\
(0.07)\end{array}$ & $\begin{array}{l}-0.13 \\
(0.09)\end{array}$ & $\begin{array}{l}-0.06 \\
(0.08)\end{array}$ & $\begin{array}{c}0.94 \\
(0.01)\end{array}$ & $\begin{array}{l}-0.06 \\
(0.08)\end{array}$ \\
\hline K6V,rir & $\begin{array}{c}0.12 \\
(0.08)\end{array}$ & $\begin{array}{c}0.58 \\
(0.06)\end{array}$ & $\begin{array}{l}-0.19 \\
(0.08)\end{array}$ & $\begin{array}{c}-0.01 \\
(0.08)\end{array}$ & $\begin{array}{c}0.04 \\
(0.08)\end{array}$ & $\begin{array}{c}0.96 \\
(0.01)\end{array}$ \\
\hline & Model & K7V,tech & K7V,ls & $\overline{\mathrm{K}} 7 \mathrm{~V}$,inf & K7V,rir & \\
\hline & K4V,tech & $\begin{array}{c}0.64 \\
(0.05)\end{array}$ & $\begin{array}{l}-0.12 \\
(0.08)\end{array}$ & $\begin{array}{c}0.12 \\
(0.09)\end{array}$ & $\begin{array}{c}0.24 \\
(0.07)\end{array}$ & \\
\hline & $\mathrm{K} 4 \mathrm{~V}, \mathrm{ls}$ & $\begin{array}{l}-0.08 \\
(0.09)\end{array}$ & $\begin{array}{c}0.37 \\
(0.07)\end{array}$ & $\begin{array}{l}-0.06 \\
(0.08)\end{array}$ & $\begin{array}{c}0.54 \\
(0.06)\end{array}$ & \\
\hline
\end{tabular}

Notes: Standard error in parenthesis. See Tables 1 and 4 for abbreviations. 
The technology measure of $\mathrm{K} 4 \mathrm{~V}$ is correlated to the $\mathrm{G} 2 \mathrm{~V}$ measure with a coefficient of 0.88 , whereas it is virtually uncorrelated with the G2V nontechnology measure as reported in Table 6. The correlation between the K7V technology measure and the G2V technology measure is 0.63 in spite of the large difference in the number of variables included in the models. It is important to note, however, that the K7V technology measure is also weakly negatively correlated to the G2V nontechnology measure with a coefficient of -0.40 (see Table $6)$.

A strong relationship between the technology measures of $\mathrm{G} 5 \mathrm{~V}$ and $\mathrm{K} 7 \mathrm{~V}$ can be established based on the high reported correlation in Table 9, but these estimated measures are both partly mingled with the estimated real-interest-rate measure of the other model. Given that the included variables and imposed identificiation restrictions in G5V constitute just a subset of the ones in $\mathrm{K} 7 \mathrm{~V}$, we interpret this finding as a weakness of G5V which follows from the lack of consumption, investment and real ratio relationships in the VAR system.

Labor-Supply Shocks Although the correlation between the estimated G5V and K7V labor-supply shocks is high and those are unrelated to the other estimated shocks, the correlation between the estimated G5V and K4V labor-supply shocks is low and statistically insignificant as reported in Table 9, the correlation coefficient being merely 0.11, although the same identification restriction is imposed in all of the three models for identifying these shocks. This result can be attributed to the fact that K4V does not comprise the monetary variables real balances, nominal (or real) interest rate and inflation. The existence of these variables is obviously crucial for distinguishing the labor-supply shocks from the inflation and real-interest-rate shocks. Otherwise, the labor-supply measure, as that for $\mathrm{K} 4 \mathrm{~V}$, is mingled with monetary phenomena. Notice, for example, that the estimated labor-supply shocks of $\mathrm{K} 4 \mathrm{~V}$ are significantly correlated with the estimated inflation and real-interest-rate shocks of G5V. Furthermore, we can extract from Table 8 that the labor-supply shock of K4V is correlated to the K7V real-interest-rate shock with an estimated coefficient of 0.54 .

Dynamic Effects of Technology and Labor-Supply Shocks The results presented up to now occasionally emphasize strong estimated correlations. It should, however, be re- 
Table 9: Correlations among identified shocks of G5V and modified KPSW models

\begin{tabular}{ccc}
\hline \hline Model & K4V,tech & K4V,ls \\
\hline G5V,tech & 0.75 & 0.08 \\
& $(0.04)$ & $(0.08)$ \\
G5V,ls & -0.05 & 0.11 \\
& $(0.08)$ & $(0.09)$ \\
G5V,inf & 0.05 & 0.35 \\
& $(0.09)$ & $(0.06)$ \\
G5V,ri & -0.04 & 0.34 \\
& $(0.08)$ & $(0.08)$ \\
\hline
\end{tabular}

\begin{tabular}{ccccc}
\hline \hline Model & K7V,tech & K7V,ls & K7V,inf & K7V,rir \\
\hline G5V,tech & 0.76 & -0.04 & 0.01 & 0.36 \\
& $(0.03)$ & $(0.08)$ & $(0.09)$ & $(0.07)$ \\
G5V,ls & -0.06 & 0.80 & 0.22 & -0.10 \\
& $(0.07)$ & $(0.03)$ & $(0.08)$ & $(0.08)$ \\
G5V,inf & -0.15 & -0.02 & 0.71 & 0.50 \\
& $(0.08)$ & $(0.08)$ & $(0.07)$ & $(0.05)$ \\
G5V,rir & -0.34 & 0.09 & -0.47 & 0.67 \\
& $(0.08)$ & $(0.09)$ & $(0.04)$ & $(0.06)$ \\
\hline
\end{tabular}

Notes: Standard error in parentheses. See Tables 1 and 4 for abbreviations. 
minded that a strong correlation indicates merely that the corresponding impulse response functions are qualitatively similar, but they may nevertheless be quantitatively quite different. Panel A in Figure 7 shows the dynamic response of output to a one-standard-deviation technology shock in the "unbiased" models G2V, G5V, K4V and K7V. ${ }^{20}$ Although the relevant correlation coefficients in Table 5 are rather high and the dynamic responses look qualitatively similar, they differ quite a bit in some details and in scale. These differences may have important implications on the estimated shares of structural shocks in cyclical fluctuations. Panel B in Figure 7 reinforces our reasoning above that the inclusion of monetary variables in the VAR is very important for the identification of labor-supply shocks, but the inclusion of the great-ratios is not.
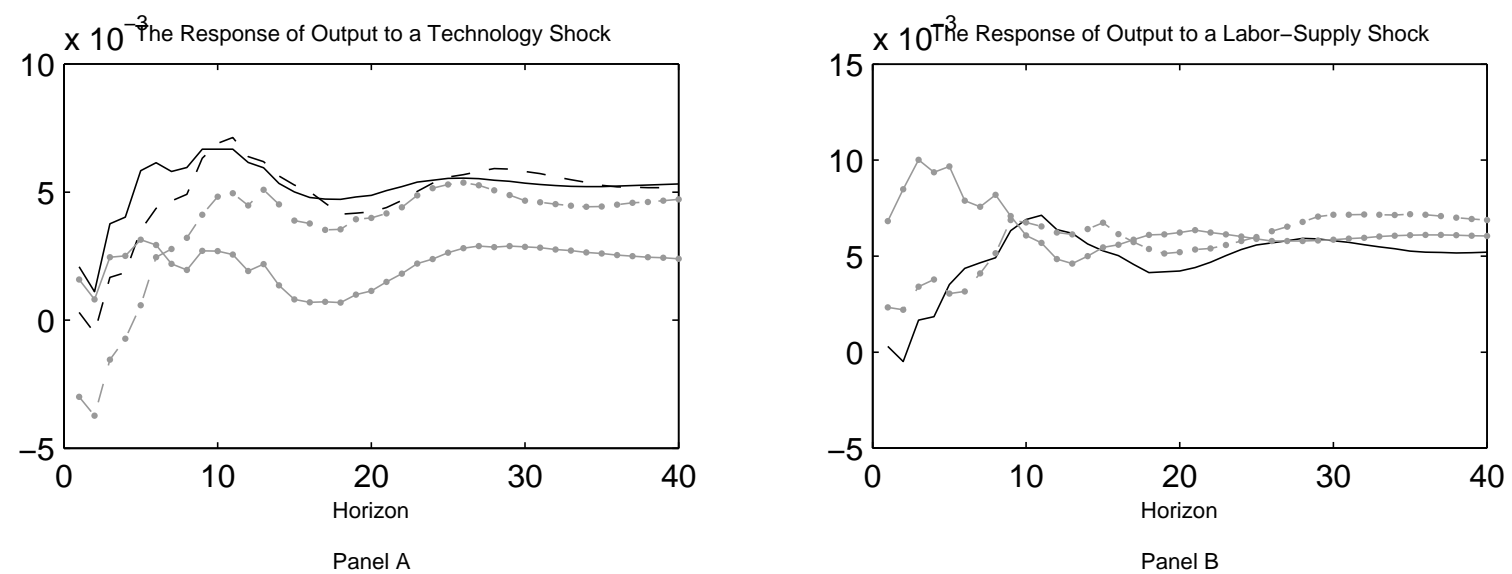

Figure 7: Dynamic response of output to a technology shock and a labor-supply shock. Responses in $\mathrm{G} i \mathrm{~V}$ are black, $\mathrm{K} i \mathrm{~V}$ grey. Legend for Panel A: G2V (solid), G5V (dashed), K4V(pointed-solid), K7V(pointed-dashed). Legend for Panel B: G5V (solid), K4V(pointedsolid), K7V(pointed-dashed).

Inflation and Real-Interest-Rate Shocks The estimated nontechnology shock of the bivariate Gali model stands generally for a real-interest-rate measure as can be concluded from Tables 4 and 6. Nevertheless, the distinction between inflation and real-interest-rate shocks in G5V is not as clear, apparently because of the lack of consumption and investment in this VAR. Note that the estimated inflation and real-interest-rate shocks of K6V and

\footnotetext{
${ }^{20}$ These models are at least approximately unbiased in identifying the technology shocks according to the arguments presented in this paper.
} 
$\mathrm{K} 7 \mathrm{~V}$ are clearly distinguishable from each other as well as from the other shocks in the corresponding VARs (see Table 8). Moreover, it can be extracted from Tables 7 and 9 that the mingling of inflation and real-interest-rate shocks between $\mathrm{G} 5 \mathrm{~V}$ and $\mathrm{K} 6 \mathrm{~V}$ also occurs between the same shocks of G5V and K7V.

Without going further into detail, we would like to note that although KPSW called the third permanent shock of their six-variable model a real-interest-rate shock, it can be interpreted as a nominal-interest-rate shock as well. Regardless whether this shock is named a real-interest-rate or a nominal-interest-rate one, it can be seen as a source of monetary (and hence demand) volatility. Therefore, the effects of both shocks are considered as a monetary phenomenon in the next section, where the role of structural shocks in the business cycle fluctuations of the macroeconomic variables is discussed.

\section{Which Shocks Explain the Fluctuations of the Variables?}

SVAR models provide an econometrician with certain tools for analyzing business cycles. Gali, for example, decomposes the historical output and the labor input series to technology and nontechnology components, filters them using the HP-filter, and establishes that the strong comovement between the business cycle components of output and labor input stems from the strong comovement of the nontechnology components. Therefore, he concludes, nontechnology shocks must be the driving force behind cyclical fluctuations. This type of reasoning is elegant, but it may be insufficient for the question considered, since comovement among macroeconomic variables is only one characteristic of the cycle. There are other ones such as duration and amplitude, and those are not taken into consideration following Gali's argumentation. Refining the nontechnology shocks into various components as we have done in this paper may lead to the finding, for example, that more than one "nontechnology" historical component of output and labor input show a strong comovement. In such a case, Gali's handling of the question becomes inadequate.

KPSW employ the conventional forecast error variance decomposition (FEVD) technique in order to deal with the same question. They report that the fraction of the forecast error variance attributable to the real-interest-rate shock of output is 74 percent in 4 quarters, 55 percent in 8 quarters and 25 percent in 24 quarters. Moreover, the contribution of the 
technology shock to output fluctuations is 5 percent in 4 quarters, 22 percent in 8 quarters and 62 percent in 24 quarters. It is obvious that the question of whether the technology shocks are more important than the real-interest-rate shocks cannot (always) be answered for the entire business cycle horizon when FEVD is employed. There are also more severe problems with using the FEVD in a business cycle context, as discussed by Seymen (2007). Therefore, we implement a historical variance decomposition in the way suggested in Seymen (2007) when investigating the sources of business cycle fluctuations in the following.

Historical Variance Decomposition (HVD) According to the FEVD example given above, given that a typical definition of the business cycle horizon is from 6 to 32 quarters, it is not possible to have an idea about the weight of real-interest-rate and technology shocks in the fluctuations of output over the entire business cycle horizon according to K6V. For example, is the share of real-interest-rate shocks 55 percent, 25 percent, or something in between? One solution to this problem is to use the HVD, which is based on the idea that the HP cyclical component of the $i^{\text {th }}$ variable in the VAR can be written as

$$
X^{i, h p}=X_{w^{1}}^{i, h p}+X_{w^{2}}^{i, h p} \cdots+X_{w^{N}}^{i, h p}
$$

where $X^{i, h p}$ is the HP cyclical component of the $i^{\text {th }}$ variable in $X$ and $X_{w^{j}}^{i, h p}$ is the component of $X^{i, h p}$ w.r.t. the $j^{\text {th }}$ structural shock. $N$ is the number of structural shocks in the system and $K \geq N .^{21}$ Then

$$
\frac{\operatorname{cov}\left(X^{h p, i}, X_{w^{j}}^{h p, i}\right)}{\operatorname{var}\left(X^{h p, i}\right)}
$$

stands for the share of the $j^{\text {th }}$ structural shock in the fluctuations of the $i^{\text {th }}$ variable computed using the HP-filter. ${ }^{22}$

Results The historical variance decomposition reestablishes the results in Gali (1999). Nontechnology shocks are the main driving force of business cycle fluctuations in output and labor input according to the bivariate model as reported in Table 10. The nontechnology

\footnotetext{
${ }^{21}$ In many examples, $K=N$. One example where this is not the case is the bivariate model of Gali (1999) with three variables and two structural shocks.

${ }^{22} \operatorname{cov}\left(X^{h p, i}, X_{w^{j}}^{h p, i}\right)$ can in principle bear a negative value. This is, however, the case only when $X_{w^{j}}^{h p, i}$ is very small relative to $X^{h p, i}$.
} 
Table 10: Shares of structural shocks in business cycle fluctuations of variables in G2V

\begin{tabular}{ccc}
\hline \hline & tech & nontech \\
\hline$y$ & 0.12 & 0.88 \\
$n$ & 0.11 & 0.89 \\
$x$ & 0.47 & 0.53 \\
\hline
\end{tabular}

Note: See Tables 1 and 4 for abbreviations.

share amounts to 0.88 and 0.89 for output and labor input, respectively. However, technology and nontechnology shocks have a balanced weight in the fluctuations of labor productivity, the share of technology shocks being 0.47 and nontechnology shocks being 0.53.

The bivariate Gali model contains only shocks with permanent effects, which is perhaps a good approximation for identifying technology shocks but arguably not the best approximation. The augmented Gali model contains four permanent shocks together with a transitory shock, and this changes the weight of permanent shocks, particularly in the fluctuations of labor productivity significantly (see Table 11). The estimated share of technology shocks in the fluctuations of labor productivity decreases to 0.33 from 0.47 in the bivariate model and the permanent shocks have a share of 0.87 . In $\mathrm{K} 7 \mathrm{~V}$, which contains the balanced-growth relationships in addition to the money demand relationship in G5V, the share of technology shocks in labor productivity fluctuations is a mere 0.18 and the total share of permament shocks is 0.63. Obviously, the augmentation of the smallest model considered in this paper, G2V, leads to substantial changes in terms of the explanatory power of technology shocks and permanent shocks for the fluctuations of productivity.

The role of technology shocks in the fluctuations of output and labor input is nevertheless not affected by more than ten percent by the augmentation of $\mathrm{G} 2 \mathrm{~V}$, as can be seen by comparing the figures in Tables 10 and 11. Moreover, G5V attributes a higher share to technology shocks in the fluctuations of inflation and real interest rate than $\mathrm{K} 7 \mathrm{~V}$, but these shares are still not large.

Although the five-variable Gali model contains a transitory shock, the share of this shock in the fluctuations of real balances is virtually 0 and it is very small for the fluctuations 
Table 11: Shares of structural shocks in business cycle components of variables in G5V and $\mathrm{K} 7 \mathrm{~V}$

\begin{tabular}{c|ccccc|ccccc}
\hline \hline & tech & ls & inf & rir & sum & tech & ls & inf & rir & sum \\
\hline$y$ & 0.09 & 0.21 & 0.39 & 0.28 & 0.96 & 0.13 & 0.07 & 0.09 & 0.52 & 0.82 \\
$n$ & 0.14 & 0.27 & 0.37 & 0.21 & 0.99 & 0.25 & 0.11 & 0.07 & 0.31 & 0.74 \\
$x$ & 0.33 & 0.10 & 0.26 & 0.17 & 0.87 & 0.18 & 0.03 & 0.08 & 0.33 & 0.63 \\
$m-p$ & 0.16 & 0.56 & 0.16 & 0.12 & 1 & 0.20 & 0.29 & 0.09 & 0.17 & 0.76 \\
$\Delta p$ & 0.21 & 0.23 & 0.33 & 0.22 & 0.99 & 0.09 & 0.14 & 0.30 & 0.14 & 0.67 \\
$R$ & 0.05 & 0.29 & 0.36 & 0.24 & 0.95 & 0.06 & 0.14 & 0.09 & 0.50 & 0.80 \\
$R-\Delta p$ & 0.29 & 0.05 & 0.24 & 0.37 & 0.94 & 0.10 & 0.05 & 0.34 & 0.21 & 0.70 \\
\hline & & & G5V & & & & & K7V & &
\end{tabular}

Notes: sum is the total share of permanent shocks. See Tables 1 and 4 for further abbreviations.

of inflation and nominal and real interest rates. However, adding consumption, investment and the balanced-growth relationships to G5V generates a substantial change in this respect. Transitory shocks explain more than twenty percent of fluctuations of the nominal variables. Output and labor input fluctuations are also affected in the same way as the nominal variables when one jumps from G5V to K7V.

Table 12 indicates that $\mathrm{K} 6 \mathrm{~V}$ and $\mathrm{K} 7 \mathrm{~V}$ do not differ much in terms of the total share of permanent shocks in the fluctuations of macroeconomic variables, although the first model contains three and the latter model four permanent shocks. This share is even less in K7V than in $\mathrm{K} 6 \mathrm{~V}$ for output. It is striking that consumption fluctuations are driven more heavily by transitory shocks than the fluctuations of the other variables according to both $\mathrm{K} 6 \mathrm{~V}$ and $\mathrm{K} 7 \mathrm{~V}$.

Recall the example given at the beginning of this section for computing the shares of structural shocks using the FEVD technique. FEVD leads to the conclusion for output fluctuations in $\mathrm{K} 6 \mathrm{~V}$ that technology and real-interest-rate shocks are both important sources of output business cycle fluctuations. This conclusion is refuted, however, by the historical variance decomposition of output. Real-interest-rate shocks have a share of 0.66 and technology shocks have a share of merely 0.13 in the fluctuations of output according to the latter technique. This is a good example showing the amount of distortion caused by FEVD in the conclusions reached. 
Table 12: Shares of structural shocks in business cycle components of variables in K6V and $\mathrm{K} 7 \mathrm{~V}$

\begin{tabular}{|c|c|c|c|c|c|c|c|c|c|}
\hline & tech & $\overline{\text { inf }}$ & rir & sum & tech & ls & $\overline{\text { inf }}$ & rir & sum \\
\hline$y$ & 0.13 & 0.06 & 0.66 & 0.86 & 0.13 & 0.07 & 0.09 & 0.52 & 0.82 \\
\hline$c$ & 0.08 & 0.06 & 0.40 & 0.54 & 0.10 & 0.12 & 0.10 & 0.33 & 0.64 \\
\hline$i$ & 0.15 & 0.16 & 0.54 & 0.86 & 0.09 & 0.10 & 0.19 & 0.43 & 0.81 \\
\hline$m-p$ & 0.46 & 0.07 & 0.25 & 0.77 & 0.20 & 0.29 & 0.09 & 0.17 & 0.76 \\
\hline$\Delta p$ & 0.23 & 0.29 & 0.14 & 0.66 & 0.09 & 0.14 & 0.30 & 0.14 & 0.67 \\
\hline$R$ & 0.13 & 0.09 & 0.56 & 0.77 & 0.06 & 0.14 & 0.09 & 0.50 & 0.80 \\
\hline$R-\Delta p$ & 0.14 & 0.33 & 0.16 & 0.62 & 0.10 & 0.05 & 0.34 & 0.21 & 0.70 \\
\hline & \multicolumn{4}{|c|}{ K6V } & \multicolumn{5}{|c|}{$\mathrm{K} 7 \mathrm{~V}$} \\
\hline
\end{tabular}

Note: See Tables 1, 4 and 11 for abbreviations.

The fluctuations of output, consumption and investment are mainly driven by realinterest-rate shocks according to both $\mathrm{K} 6 \mathrm{~V}$ and $\mathrm{K} 7 \mathrm{~V}$. Yet this weight is less emphasized in $\mathrm{K} 7 \mathrm{~V}$ than in $\mathrm{K} 6 \mathrm{~V}$. It of course cannot be ruled out that there is a transitory shock that has a higher share than the real-interest-rate shock for these variables. The role of the transitory shocks is, however, beyond the scope of this study.

Given that all the other models considered in this paper are a subset of K7V, K7V is likely to be superior to the other models in terms of explaining the structural shocks and their effects on the variables. Table 13 shows the shares of permanent supply shocks, technology and labor-supply, and permanent demand shocks, inflation and real-interest-rate, according to $\mathrm{K} 7 \mathrm{~V}$. The former group of shocks have a share of 0.36 , which is close to the share of the permanent demand shocks, 0.38, in labor input fluctuations. In fluctuations of all the other variables except real balances, the permanent demand shocks dominate the cyclical fluctuations. Demand shocks have shares of 0.61 and 0.62 respectively in output and investment fluctuations, whereas their dominance in fluctuations of consumption is less emphasized with a share of 0.43 . Demand shocks also drive to a large extent the fluctuations of the nominal variables inflation and nominal and real interest rates.

A finding that is perhaps puzzling at first sight is that the fluctuations of real balances are driven mainly by supply, but not demand shocks. The total share of technology and labor-supply shocks is 0.49 for this variable, whereas the total share of real-interest-rate and 
Table 13: Shares of permanent supply and demand shocks in business cycle components of variables in $\mathrm{K} 7 \mathrm{~V}$

\begin{tabular}{cccccccccc}
\hline \hline & $y$ & $c$ & $i$ & $n$ & $x$ & $m-p$ & $\Delta p$ & $R$ & $R-\Delta p$ \\
\hline Supply & 0.20 & 0.22 & 0.19 & 0.36 & 0.21 & 0.49 & 0.23 & 0.20 & 0.15 \\
Demand & 0.61 & 0.43 & 0.62 & 0.38 & 0.41 & 0.26 & 0.44 & 0.59 & 0.55 \\
\hline
\end{tabular}

Notes: Technology and labor-supply shocks constitute the permanent supply shocks. Inflation and real-interest-rate shocks constitute the permanent demand shocks. See Table 1 for abbreviations.

inflation shocks does not exceed 0.26. This puzzle is even more emphasized in G5V, where the total share of supply shocks is 0.72 in the fluctuations of real balances. Moreover, in both K7V and G5V, labor-supply shocks turn out to have the largest share, at least among the permanent shocks, for this variable. ${ }^{23}$ A possible reason for this finding could be that the monetary authority reacts to supply shocks by using the circulated amount of money as the policy instrument and to demand shocks by using the interest rates as the policy instrument.

\section{Conclusion}

According to Blanchard and Quah (1993), "the entire point of structural VAR analysis is exactly identification of alternative disturbances". Thus, "all possibilities need to be considered". Although it is not possible to consider all possibilities in one paper, more possibilities than suggested up to now in a part of the literature have been investigated in this paper. The ultimate aim has been to estimate the shares of different sources in the business cycle fluctuations of some macroeconomic variables more reliably.

The findings of Alexius and Carlsson $(2001,2005)$ have served as the starting point of the investigation. These authors compared the technology measures estimated using the bivariate Gali (1999) and the three-variable and six-variable KPSW models with the ones estimated using the production function approach. They established that the Gali framework is successful in identifying the technology shocks, but not the KPSW framework. The threevariable and six variable KPSW models have therefore been augmented with labor input (and

\footnotetext{
${ }^{23} \mathrm{~K} 6 \mathrm{~V}$ implies the same conclusion when the bias discussed in the last section is taken into account.
} 
hence indirectly with labor productivity) and with the theoretical identification restriction of Gali in order to overcome the bias in the KPSW framework in this study. One interesting finding has been that the nature of the computed technology measure does not change much when a basic model that includes labor input and the identification approach of Gali for technology shocks, like the bivariate Gali or four-variable KPSW model, is extended with nominal variables.

Nontechnology shocks are clearly the main driving force behind cyclical fluctuations according to our findings. In particular, permanent demand shocks have been found to be important in the fluctuations of real variables like output, consumption and investment. Surprisingly though, the business cycle fluctuations of real balances are explained much better by permanent supply shocks, i.e., technology and labor-supply, than by demand shocks. Although this comparison has been made in the current framework only among the permanent shocks, the finding is still striking. The investigation of the mechanisms that lead to this finding is left to future studies.

Finally, the role played by transitory shocks in the fluctuations of macroeconomic variables is for all of the variables smaller than the role of permanent shocks according to the largest and most encompassing model that has been considered here. This implies that most of the business cycle fluctuations occur when macroeconomic variables converge to new equilibria due to permanent shocks. 


\section{References}

Alexius, A. and M. Carlsson (2001) "Measures of Technology and the Business Cycle: Evidence from Sweden and the U.S.," FIEF Working Paper Series, No. 174

Alexius, A. and M. Carlsson (2005) "Measures of Technology and the Business Cycle," The Review of Economics and Statistics, 87, No. 2, 299-307

Basu, S. and M.S. Kimball (1997) "Cyclical Productivity with Unobserved Input Variation," NBER Working Paper, No. 5915

Bayoumi, T. and B. Eichengreen (1992) "Shocking Aspects of European Monetary Unification," NBER Working Paper, No. 3949

Blanchard, O.J. and D. Quah (1989) "The Dynamic Effects of Aggregate Demand and Supply Disturbances," The American Economic Review, Vol.79, No. 4, 655-673

Breitung, J. (2000) "Structural Inference in Cointegrated Vector Autoregressive Models," Habilitation Thesis, Humboldt University Berlin

Christiano, L.J., Eichenbaum, M. and C.L. Evans (1999) "Monetary Policy Shocks: What Have We Learned and to What End?" in Handbook of Macroeconomics, M. Woodford and J. Taylor, eds., Vol. 1A, Amsterdam: North Holland

Christiano, L.J., Eichenbaum, M. and R.Vigfusson (2003) "What Happens After a Technology Shock," NBER Working Paper, No. 9819

Erceg, C., Guerrieri, L. and C. Gust (2005) "Can Long-Run Restrictions Identify Technology Shocks?," Journal of the European Economic Association, Vol. 3, No. 6, 1237-1278

Faust, J. and E. Leeper (1997) "When Do Long-Run Identifying Restrictions Give Reliable Results," Journal of Business and Economic Statistics, Vol. 15, No. 3, 345-353

Gali, J. (1999) "Technology, Employment and the Business Cycle: Do Technology Shocks Explain Aggregate Fluctuations?," The American Economic Review, Vol. 89, No. 1, 249271 
Gali, J. and P. Rabanal (2004) "Technology Shocks and Aggregate Fluctuations: How Well Does the Real Business Cycle Model Fit Postwar U.S. Data?," IMF Working Paper, $\mathrm{WP} / 04 / 234$

Jang, K. and M. Ogaki (2001) "User Guide for VECM with Long-Run Restrictions," The Ohio State University, Manuscript

King, R., Plosser, C., Stock, J. and M. Watson (1991) "Stochastic Trends and Economic Fluctuations," The American Economic Review, Vol. 81, No. 4, 819-840

Lütkepohl, H. (2005) New Introduction to Multiple Time Series Analysis, Springer, Berlin Seymen, A. (2007) "A Critical Note on the Forecast Error Variance Decomposition," Draft, University of Hamburg

Shapiro, M.D. and M. Watson (1988) "Sources of Business Cycle Fluctuations," Cowles Foundation Discussion Paper, No. 870

Stock, J. and M. Watson (1989) "A Simple MLE of Cointegrating Vectors in Higher Order Integrated Systems," NBER Technical Working Paper, No. 83 